\title{
High prevalence of undernutrition and low dietary diversity in institutionalised elderly living in Sri Lanka
}

\author{
Kumari M Rathnayake ${ }^{1,2, *}$, MPPM Wimalathunga ${ }^{1}$, Michelle Weech ${ }^{2}$, Kim G Jackson ${ }^{2}$ \\ and Julie A Lovegrove ${ }^{2}$ \\ 'Department of Applied Nutrition, Faculty of Livestock, Fisheries \& Nutrition, Wayamba University of Sri Lanka, \\ Makandura 60170, Sri Lanka: ${ }^{2}$ Hugh Sinclair Unit of Human Nutrition and Institute for Cardiovascular and \\ Metabolic Research, Department of Food and Nutritional Sciences, University of Reading, Reading, UK
}

Submitted 25 May 2014: Final revision received 29 December 2014: Accepted 3 February 2015: First published online 1 April 2015

\begin{abstract}
Objective: The present study aimed to assess nutritional status, dietary diversity and lifestyle risk factors associated with undernutrition in an institutionalised Sri Lankan elderly population.

Design: The study was of cross-sectional design followed by a stratified sampling method.

Setting: Twelve homes for the elderly recruited from six provinces in Sri Lanka. Subjects: A total of 311 institutionalised elderly aged $\geq 60$ years.

Results: The mean age of the study population was 75 (SD 8) years. Prevalence of undernutrition was $30 \%$. Mean food variety score, dietary diversity score and dietary serving score of the study population were $8 \cdot 7$ (SD 1.5), 7.3 (SD 1.2) and 10.9 (SD 2.0), respectively. Mean daily intakes of fruit, vegetables, meat, fish, eggs and pulses and dairy portions were below the national recommendations, whereas the mean consumption of sugar exceeded the national recommendation. Only the mean intake of starch was within the recommendation. Food allergies $(\mathrm{OR}=8 \cdot 0 ; 95 \%$ CI 3.9, 16.2), skipping meals (OR=3.8; $95 \% \mathrm{CI} 2 \cdot 0,7 \cdot 5)$ and lack of leisure activities (OR $=3 \cdot 1 ; 95 \%$ CI $1 \cdot 5,6 \cdot 7)$ significantly increased the risk of undernutrition, whereas the use of dentures decreased the risk (OR $=0 \cdot 20 ; 95 \% \mathrm{CI}$ 0.06, 0.69).

Conclusions: High prevalence of undernutrition and low dietary diversity were observed in an institutionalised elderly Sri Lankan population. Therefore, there is an urgent need to implement nutrition interventions as part of geriatric care to reduce undernutrition and improve the diets of the institutionalised elderly population in Sri Lanka.
\end{abstract}

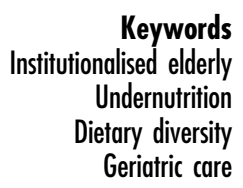

Globally, the prevalence of the elderly population (>60 years) has increased gradually over the past few decades. In Sri Lanka it accounts for $12.3 \%$ of the total population $^{(1)}$, which is the fastest growing elderly population in South East Asia ${ }^{(2,3)}$. It is well documented that worldwide there is a higher prevalence of malnutrition in the institutionalised elderly compared with the free-living elderly $^{(4-7)}$. Existing literature suggests that nutritional status has a major impact on the health and functional status of older individuals. Furthermore, biological, physiological, social and psychological changes often accompanying ageing along with increased prevalence of morbidities enhance the susceptibility of the elderly to be malnourished $^{(8)}$. The aetiology of malnutrition is multifactorial in older people. Evidence indicates that the elderly are at risk of nutritional deficiencies due to changes in body composition, the gastrointestinal tract, sensory function, and fluid and electrolyte regulation, and from chronic illness, medication, hospitalisation and psychosocial factors, such as financial restrictions, social isolation, widowhood and bereavement, food anxieties and decreasing independence ${ }^{(9)}$. Nutritional status is a key determinant of the quality of life, morbidity and mortality of older people.

In Sri Lanka, pre- and primary-school children, adolescents and pregnant mothers are recognised as nutritionally vulnerable populations. Sri Lanka and other counties are currently experiencing an increasing ageing population as a result of declining fertility and mortality rates. Siddhisena reported that during the last two decades the number of institutionalised older people has risen considerably, suggesting a growing demand for care ${ }^{(10)}$. Furthermore, recent 
studies performed in India and Malaysia showed a higher prevalence of malnutrition in the institutionalised elderly ${ }^{(4,11)}$. It is evident that the elderly, particularly those who are institutionalised, require specific attention and should be a priority in public health nutrition intervention programmes. Thus, the prevalence of and risk factors associated with undernutrition in different elderly populations need to be investigated to determine suitable nutritional therapies to combat undernutrition in these population groups. The aim of the present study was to assess nutritional status, dietary diversity and lifestyle risk factors associated with undernutrition in an institutionalised elderly population from Sri Lanka.

\section{Methods}

\section{Study design and participants}

The study was conducted with a cross-sectional design followed by a stratified sampling method. Ethical clearance was obtained from the Ethical Review Committee of the Sri Lanka Medical Association (ERC/13-037). The study aimed to recruit 300 elderly men and women, with an expected prevalence of $20 \%$, with a power of $95 \%$ and a $5 \%$ significance level, which included a drop-out rate of $10 \%{ }^{(12)}$. A total of 311 older adults (aged $\geq 60$ years) were recruited from twelve homes for the elderly from six provinces, which were considered as primary units, in Sri Lanka. The six provinces were Western, North Western, Sabaragamuwa, Central, Northern and Eastern province. A list of all registered elders' homes in each province was obtained from the relevant provincial social services departments and from this list two elderly homes were randomly selected as secondary units. Elders invited to participate purposively included those who could communicate, did not have any cognitive impairment and were able to carry out a face-to-face interview for approximately $40 \mathrm{~min}$. The selected elderly homes were initially contacted via telephone by the study team who explained the study and verbal consent was taken. Elderly homes were visited randomly (including both weekdays and weekend days) to minimise data bias. All participants provided written informed consent prior to data collection. An interviewer-administered questionnaire was used to collect information regarding sociodemographic status (age, gender, level of education and financial status), physiological factors (appetite loss, tooth loss, use of dentures and vision impairment), psychological factors (presence of depression as defined by lack of interest or pleasure in life, lack of engagement with friends, caregivers and day-to-day activities, low mood and frequent negative thoughts), lifestyle factors (ability to move, leisure activities, usage of medication and betel chewing) and dietary risk factors (skipping meals, ability to eat and food allergy). The presence of food allergy was self-reported but not necessarily clinically diagnosed.

\section{Anthropometry}

Anthropometric measurements, including height, body weight, mid-upper arm circumference (MUAC) and calf circumference (CC), were obtained by trained investigators using standard equipment according to standard guidelines ${ }^{(13)}$. Participants were asked to remove jackets, shoes and jewellery, and empty their pockets, before body weight was measured using a calibrated electronic scale (Seca 813, Hamburg, Germany), accurate to the nearest $0 \cdot 1 \mathrm{~kg}$, which was placed on an even concrete floor. Height was measured to the nearest $0 \cdot 1 \mathrm{~cm}$ with an upright plastic portable stadiometer (Invicta Plastics model IP0955, Leicester, UK) while the participant was in a standing position without footwear. BMI was calculated as weight divided by height ${ }^{2}\left(\mathrm{~kg} / \mathrm{m}^{2}\right)$. According to the WHO cut-off values for Asians, a BMI of $\leq 18.5 \mathrm{~kg} / \mathrm{m}^{2}$ is considered a marker of undernutrition ${ }^{(14)}$. A nonstretchable measuring tape was used to assess MUAC, which was taken at the midpoint between the acromial process of the scapula and olecranal process of the elbow of the non-dominant arm when the forearm was hanging relaxed at the side. The two categories of MUAC were: (i) $<21 \mathrm{~cm}$ and (ii) $\geq 21 \mathrm{~cm}$, with $<21 \mathrm{~cm}$ being an indicator of undernutrition ${ }^{(15)}$. CC, considered the most sensitive measure of muscle mass in the elderly ${ }^{(16)}$, was measured with the participant sitting in a chair with the knee and corresponding ankle kept bent to a $90^{\circ}$ angle. The researcher knelt beside the lateral side of the left calf and a loop of measuring tape was placed around the calf. When the largest circumference was located, by moving the loop up and down the calf, the tape was pulled snugly around the calf. This measurement was recorded to the nearest $0 \cdot 1 \mathrm{~cm}$, two consecutive measurements were taken and the mean circumference recorded $^{(15)}$. As categorised in the Mini Nutritional Assessment tool ${ }^{(17)}$, the two categories of CC were set as: (i) $<31 \mathrm{~cm}$ and (ii) $\geq 31 \mathrm{~cm}$.

\section{Dietary diversity}

A single $24 \mathrm{~h}$ dietary recall was used to assess dietary intake. The recalls were taken on random days (weekday or weekend day) by a trained researcher to minimise dayto-day variation. All foods and drinks consumed on the previous day were obtained in direct chronological order by following the standard protocol of a multiple-pass recalling technique ${ }^{(18)}$. In addition, detailed descriptions of the foods, cooking method and brand names of some foods, such as milk and processed foods, were recorded. Food intake was obtained using standard household measures, such as coconut-shell serving spoons, tablespoons, teaspoons, bowls, glasses and teacups. To assist the participants in accurately reporting the intake of foods, a series of food portion size photographs and food models prepared by the researcher were shown. For each participant, all food and drink items consumed were assigned to one of the major food groups as described in the Sri 
Lankan food-based dietary guidelines ${ }^{(19)}$. These food groups were: (i) cereal or equivalents (starchy foods); (ii) vegetables; (iii) fruits; (iv) meat, fish, eggs and pulses; (v) dairy; and (vi) added sugars. The quantity of household measures for one serving of food in the selected food groups was obtained as defined by Jayawardena et al. ${ }^{(20)}$. For each food group, the quantity of household measures of food consumed was divided by the quantity of household measure for one serving and summed to derive the total number of servings consumed. Composite food dishes were disaggregated into their ingredients and those ingredients were assigned to the appropriate food groups for calculating the number of servings. The dietary diversity of the study population was assessed by a food variety score (FVS; a simple count of food items consumed), dietary diversity score (DDS; a simple count of food groups consumed out of twelve groups considered) and dietary serving score (DSS; number of portions of different food groups in conformity with dietary guidelines of Sri Lanka) ${ }^{(21)}$.

\section{Data analysis}

Data were analysed using the statistical software package IBM SPSS Statistics version 21. In all analyses, a $P$ value $<0.05$ was considered as statistically significant. Both univariable and multivariable logistic regression analyses were performed to determine the risk factors associated with undernutrition. Data presented represent mean and standard deviation, unless otherwise specified.

\section{Results}

The study sample consisted of $45 \%$ men ( $n$ 140) and $55 \%$ women ( $n$ 171). The mean age of the study population was 75 (SD 8) years. The sociodemographic and anthropometric characteristics of the study population are shown in Tables 1 and 2, respectively. The mean BMI, MUAC and CC of the participants were 21.5 (SD 4.8$) \mathrm{kg} / \mathrm{m}^{2}, 23.4$ (SD 3.5$) \mathrm{cm}$ and $28.3(\mathrm{sD} 3.7) \mathrm{cm}$, respectively. The prevalence of $\mathrm{BMI}<18.5 \mathrm{~kg} / \mathrm{m}^{2}$ to determine undernutrition was $30 \%$. Prevalence of MUAC $<21 \mathrm{~cm}$ and $\mathrm{CC}<31 \mathrm{~cm}$ was $23 \%$ and $74 \%$, respectively (Table 2 ).

Mean FVS, DDS and DSS of the study population were 8.7 (SD 1.5), 7.3 (SD 1.2) and 10.9 (SD 2.0), respectively, with similar mean values in men and women (respectively, 8.8 ( $\mathrm{SD} 1.5$ ) and 8.5 (SD 1.5) for FVS, 7.4 (SD 1.1) and 7.2 (SD 1.2) for DDS, and 10.8 (SD 1.9) and $11 \cdot 0$ (SD 2.1) for DSS). Undernourished elderly had a lower median DSS compared with their nourished counterparts. The nourished elderly had maximum of DSS of 16, whereas in the undernourished elderly it was approximately 13 .

Mean daily intakes of fruit, vegetables, meat, fish, eggs and pulses and dairy were below the national recommendations for the Sri Lankan population (Table 3),
Table 1 Sociodemographic characteristics of the institutionalised elderly Sri Lankan population

\begin{tabular}{|c|c|c|c|c|c|c|}
\hline \multirow[b]{2}{*}{ Characteristic } & \multicolumn{2}{|c|}{ All } & \multicolumn{2}{|c|}{ Men } & \multicolumn{2}{|c|}{ Women } \\
\hline & $\%$ & $n$ & $\%$ & $n$ & $\%$ & $n$ \\
\hline Gender & 100 & 311 & 45 & 140 & 55 & 171 \\
\hline \multicolumn{7}{|l|}{ Age } \\
\hline $60-69$ years & 28 & 87 & 14 & 44 & 14 & 43 \\
\hline $70-79$ years & 44 & 137 & 17 & 53 & 27 & 84 \\
\hline$\geq 80$ years & 28 & 87 & 14 & 43 & 14 & 44 \\
\hline \multicolumn{7}{|l|}{ Level of education } \\
\hline No schooling & 32 & 99 & 9 & 29 & 23 & 70 \\
\hline Up to grade 5 & 31 & 96 & 16 & 50 & 15 & 46 \\
\hline Up to grade 10 & 31 & 97 & 17 & 52 & 14 & 45 \\
\hline GCE O level and above & 6 & 19 & 3 & 9 & 3 & 10 \\
\hline \multicolumn{7}{|l|}{ Financial assistance } \\
\hline Yes & 20 & 63 & 9 & 30 & 11 & 33 \\
\hline No & 80 & 248 & 35 & 110 & 45 & 138 \\
\hline \multicolumn{7}{|l|}{ Number of years a resident } \\
\hline $1-5$ years & 66 & 204 & 31 & 96 & 35 & 108 \\
\hline $6-10$ years & 24 & 74 & 10 & 32 & 14 & 42 \\
\hline$>10$ years & 10 & 33 & 4 & 12 & 6 & 21 \\
\hline \multicolumn{7}{|l|}{ Mobility } \\
\hline Active (walk actively) & 52 & 159 & 25 & 75 & 27 & 84 \\
\hline Less active (walk using aids) & 41 & 129 & 17 & 53 & 24 & 76 \\
\hline Inactive (walk with assistance) & 7 & 23 & 4 & 12 & 3 & 11 \\
\hline \multicolumn{7}{|l|}{ Presence of chronic diseases } \\
\hline Yes & 59 & 182 & 22 & 68 & 37 & 114 \\
\hline No & 41 & 129 & 23 & 72 & 18 & 57 \\
\hline \multicolumn{7}{|l|}{ Presence of acute illness } \\
\hline Yes & 19 & 59 & 11 & 33 & 8 & 26 \\
\hline No & 81 & 252 & 34 & 107 & 47 & 145 \\
\hline \multicolumn{7}{|l|}{ Use of medication } \\
\hline Yes & 66 & 206 & 26 & 82 & 40 & 124 \\
\hline No & 34 & 105 & 19 & 58 & 15 & 47 \\
\hline \multicolumn{7}{|l|}{ Betel chewing } \\
\hline Yes & 37 & 115 & 21 & 64 & 16 & 51 \\
\hline No & 63 & 196 & 24 & 76 & 39 & 120 \\
\hline
\end{tabular}

GCE, General Certificate of Education.

Table 2 Anthropometric characteristics of the institutionalised elderly Sri Lankan population

\begin{tabular}{lcccc}
\hline Factor & Mean & SD & $\%$ & $n$ \\
\hline BMI $\left(\mathrm{kg} / \mathrm{m}^{2}\right)$ & 21.5 & 4.8 & - & - \\
$<18.5$ & 16.6 & 1.4 & 30 & 94 \\
$\geq 18.5$ & 23.6 & 4.1 & 70 & 217 \\
MUAC $(\mathrm{cm})$ & 23.4 & 3.5 & - & - \\
$<21$ & 19.4 & 1.3 & 23 & 72 \\
$\geq 21$ & 24.6 & 3.0 & 77 & 239 \\
CC $(\mathrm{cm})$ & 28.3 & 3.7 & - & - \\
$<31$ & 26.7 & 2.7 & 74 & 229 \\
$\geq 31$ & 32.8 & 2.1 & 26 & 82 \\
\hline
\end{tabular}

MUAC, mid-upper arm circumference; CC, calf circumference.

whereas the mean consumption of sugar appeared to exceed the national recommendation. Only the mean intake of starch was within the recommendations (Table 3).

Food allergies, skipping meals and lack of leisure activities significantly increased the risk of undernutrition, whereas the use of dentures decreased the risk in both univariable and multivariable logistic regression analyses (Table 4). 
Table 3 Mean food intakes of the institutionalised elderly Sri Lankan population by food group and comparison with national Sri Lankan dietary recommendations

\begin{tabular}{lcc}
\hline Food group & Mean intake (portions/d) & National recommendation (portions/d) $^{*}$ \\
\hline Cereal or equivalents (starchy foods) & 8.24 & $6-11$ \\
Fruits & 0.46 & $2-3$ \\
Vegetables & 1.49 & $3-5$ \\
Fruits and vegetables & 1.95 & $\geq 5$ \\
Meat, fish, eggs and pulses & 1.56 & $3-4$ \\
Dairy (milk and/or milk products) & 0.55 & $1-2$ \\
Added sugar & 3.71 & Sparingly \\
\hline
\end{tabular}

${ }^{\star}$ Food-based dietary guidelines for Sri Lankans ${ }^{(19)}$.

Table 4 Factors associated with undernutrition in the institutionalised elderly Sri Lankan population

\begin{tabular}{|c|c|c|c|c|c|}
\hline \multirow[b]{2}{*}{ Factors } & \multicolumn{2}{|c|}{ Univariable analysis } & \multicolumn{3}{|c|}{ Multivariable analysis* } \\
\hline & OR & $P$ value & OR & $P$ value & $95 \% \mathrm{Cl}$ \\
\hline Skipping meals & 6.08 & $<0.0001$ & 3.84 & $<0.0001$ & $1.971,7.500$ \\
\hline Food allergies & $10 \cdot 16$ & $<0.001$ & 8.01 & $<0.0001$ & $3.948,16.236$ \\
\hline Loss of appetite & $2 \cdot 19$ & 0.002 & 1.55 & 0.167 & $0.833,2 \cdot 876$ \\
\hline Lack of leisure activities & 3.78 & $<0.0001$ & 3.19 & 0.002 & $1.517,6.703$ \\
\hline Lack of pleasure or interest (symptoms of depression) & $2 \cdot 61$ & $<0.0001$ & $1 \cdot 19$ & 0.592 & $0.634,2 \cdot 222$ \\
\hline Wearing dentures & 0.28 & 0.019 & 0.20 & 0.011 & $0.057,0.694$ \\
\hline
\end{tabular}

${ }^{*}$ Odds ratios, $P$ values and $95 \%$ confidence intervals were obtained from corresponding multivariable binary logistic regression analysis. Significant values in multivariable binary logistic regression analysis are given in bold font.

\section{Discussion}

Numerous risk factors for undernutrition among the elderly have been identified, with many studies performed in developed countries where the ageing population is escalating. However, there is an urgent need for these risk factors to be pre-tested and modified if required for application in Asian populations since there are apparent differences in anthropometric indicators, lifestyle and food patterns among different ethnic groups. Both the risk factors for and prevalence of undernutrition among institutionalised elderly people in Sri Lanka remain poorly understood.

In the present study, the institutions studied were nonpaying homes for the elderly. The majority were managed by religious and non-government organisations, philanthropic families or trusts, while others were financially assisted by the Ministry of Social Services of Sri Lanka. The food offered to the residents was prepared by the institution, with the exception of food provided by visitors on special occasions. The majority of the institutions had set menus for three daily meals, which were not prepared with nutrition requirement or dietary diversity considerations. The variety of foods offered on the menus was dependent on the financial resources of the institution. The current study demonstrated that undernutrition is common among a representative sample of institutionalised elderly residents across Sri Lanka. Using BMI as a useful approximate anthropometric indicator to determine undernutrition in the elderly ${ }^{(22)}$, nearly one-third (30\%) of the studied residents were identified as being undernourished, with a similar prevalence among men (28.6\%) and women (31.6\%). According to the WHO cutoffs $^{(15)}, 23 \%$ of the institutionalised elderly in the present study had a lower MUAC than recommended if sufficiently nourished, which suggests declining muscle mass and fat stores. Sarcopenia, which is the decline in muscle mass, is a major physiological condition that is predominantly found with increasing age. Although the aetiology of sarcopenia remains unclear, physical inactivity, inadequate dietary protein and/or impaired protein utilisation have been identified as indirect factors that contribute to declining muscle mass ${ }^{(23)}$. In this study group, protein-rich food consumption was below the national recommendations. Additionally, based on the cut-off defined from the Mini Nutritional Assessment tool ${ }^{(17)}, 74 \%$ had a CC of $\leq 31 \mathrm{~cm}$. Previous studies identified $\mathrm{CC}$ as a potential marker of physical function, which provides valuable information on muscle-related disability and physical function $^{(16)}$. High prevalence of low CC showed weakness in leg strength and physical function in this population.

Dietary diversity, used as a simple tool to identify those at risk of food and nutrition insecurity ${ }^{(24,25)}$ and as a marker of population micronutrient status ${ }^{(21)}$, was assessed using three measures: FVS, DDS and DSS. A recent study conducted in Sri Lanka demonstrated that FVS, DDS and DSS were useful proxy indicators of nutrient adequacy of elderly people ${ }^{(26)}$. Macro- and micronutrient deficiencies are public health concerns in Sri Lanka due to the monotonous, cereal-based diets that lack diversity. Several studies have shown that the overall nutritional quality as well as nutrient adequacy of the diet is improved with a 
diverse diet ${ }^{(27-30)}$. DDS is a major element of a highquality diet as it represents the variety of the diet. In the current study, none of the dietary diversity measures of the study sample met the optimum level (DDS was approximately 7 out of 12 food groups considered) suggesting that both the quality and quantity of their diets were poor. Only cereal consumption was within the recommendations. Noticeably, consumption of fruits, vegetables, dairy and animal foods were substantially lower than the minimum national recommendations. Since the quality and quantity of the diet are inadequate, there is a higher tendency of developing both macro- and micronutrient deficiencies among the study sample. When comparing the dietary diversity indicators (FVS, DDS and DSS) of undernourished and nourished elderly people, there was no significant difference in terms of FVS and DDS. However, as expected, the DSS of the undernourished elderly was less than that of nourished elderly. Although the number of different food groups consumed by both the undernourished and nourished elders was similar, the diversity of different food groups consumed by the undernourished elderly was less than that of the nourished elderly. Moreover, consumption of fruits, both fruits and vegetables, meat, fish and egg portions per day were relatively lower among the undernourished elderly than among the nourished elderly.

The nutrition and behaviour risk factors associated with the prevalence of undernutrition in the institutionalised elderly from the present study were in line with those of previous studies ${ }^{(31-33)}$. The elderly who experienced a loss of appetite were $2 \cdot 2$ times more likely to be undernourished than those who retained their appetite. There are many mechanisms by which appetite loss might confer an increased risk of undernutrition among the elderly. Studies have reported that with increasing age, the ability to visualise, smell and taste foods decreases ${ }^{(34,35)}$ and there are distinct changes in gastrointestinal function, which likely reduces motility rates and disrupts digestion or absorption $^{(9,36,37)}$. All of these age-related changes are associated with an increase in the satiety hormone cholecystokinin and a reduced feeding drive, both of which result in a loss of appetite $^{(38)}$. Supportive of previous literature ${ }^{(33)}$, the present study observed that skipping meals was significantly associated with a 3.8 times higher OR of being undernourished. Having self-reported food allergies was also identified as a risk factor for undernutrition having an OR of 8.0. The association of undernutrition in the elderly with psychological factors is of growing interest. Although multivariate analysis did not show a significant effect, the possibility is that symptoms of depression may exist. Symptoms of depression (a lack of interest and pleasure in life) were associated with a $2 \cdot 6$-fold higher risk of undernutrition in univariable analysis, which supports previous work ${ }^{(31)}$. Loneliness is associated with negative factors, including boredom, restlessness and unhappiness, and ultimately leads to a decrease in food intake. Results of the present study indicate that a lack of leisure activities was associated with 3.2 times higher risk of undernutrition, which is comparable with previous findings ${ }^{(39)}$. Moreover, we found that the use of dentures was associated with less undernutrition in elderly. In line with our findings, a recent study reported a positive association between both tooth loss and denture status and being underweight in the older elderly from Sri Lanka(32).

The strength of the present study was its diversity of homes for elders in Sri Lanka, representing six out of the nine provinces in the country. Although a single-day food record cannot be used to accurately evaluate an individual's habitual dietary intake, $24 \mathrm{~h}$ dietary recalls provide an estimate of the nutrition status of the elderly population studied. There may be biases when taking $24 \mathrm{~h}$ dietary recalls from the elders because of their memory lapses; however, in the current study, visual recognition aids were used as well as commonly used household measures to minimise the recall biases ${ }^{(40)}$. Oil and fats were not estimated in the present study. Coconut fat is the major contributor of dietary fat in Sri Lankan diets, and since coconut oil, coconut milk and/or scraped coconuts are added into composite dishes, this would have led to methodological challenges in obtaining accurate intakes of fats and oils ${ }^{(41)}$. The Mini Nutritional Assessment is one of the most widely used tools for assessing malnutrition in the elderly but has limitations in its application for non-Western and nonCaucasian populations ${ }^{(42)}$. Therefore, the modification of nutrition assessment tools according to different populations is recommended to effectively assess the nutritional status of the elderly in both developed and developing countries.

\section{Conclusion}

The prevalence of undernutrition, as determined by BMI, in the institutionalised elderly in Sri Lanka was high, and both the quantity and quality of diets failed to meet national recommendations. Self-reported food allergies, skipping meals and lack of leisure activities all significantly contributed to undernutrition. This high degree of undernutrition identified in the current study emphasises the need for the development of a tool specific to the Sri Lankan elderly population to detect emerging nutrition problems and to allow a timely intervention to prevent the occurrence of severe undernutrition in this vulnerable group.

\section{Acknowledgements}

Acknowledgements: The authors wish to thank the participants, administrators and caregivers of the homes, the elders for their enthusiastic cooperation and also the Nutrition Research Team of the Department of Applied Nutrition, Wayamba University of Sri Lanka, for their 
valuable assistance during the course of the study. The authors also wish to thank Mr S. Rahanan for coordination and the assistance given in data collection especially in Tamil-speaking participants. Financial support: This research received no specific grant from any funding agency in the public, commercial and not-for-profit sectors. Conflict of interest: None. Authorship: K.M.R. designed and managed the study, interpreted the data and drafted the manuscript. M.P.P.M.W. contributed to the data collection, data analysis and coordination of the study. M.W., K.G.J. and J.A.L. assisted in data interpretation and critical revision of the manuscript. Ethics of human subject participation: Ethical clearance for this study was obtained from the Ethical Review Committee of the Sri Lanka Medical Association (ERC/13-037).

\section{References}

1. Department of Census and Statistics, Sri Lanka (2012) Census of Population and Housing 2012. http://www. statistics.gov.lk/PopHouSat/CPH2011/Pages/Activities/Reports/ CPH_2012_5Per_Rpt.pdf (accessed August 2014).

2. Rajapakse S, Maithripala C, Ibrahim S et al. (2012) Disease patterns and care of older people in Sri Lanka. Indian J Gerontol 321, 351-366.

3. Risseeuw C (2012) Institutional care provisions for the aged in Sri Lanka and some reflections on issues of 'care' and 'company'. Int J Sociol Soc Policy 32, 695-707.

4. Chen ST, Ngoh HJ \& Harith S (2012) Prevalence of malnutrition among institutionalized elderly people in Northern Peninsular Malaysia: gender, ethnicity and age-specific. Sains Malays 41, 141-148.

5. Harris CL \& Fraser C (2004) Malnutrition in the institutionalized elderly: the effects on wound healing. Ostomy Wound Manage 50, 54-63.

6. Smoliner C, Norman K, Wagner K-H et al. (2009) Malnutrition and depression in the institutionalised elderly. $\mathrm{BrJ}$ Nutr 102, 1663-1667.

7. Suominen M, Muurinen S, Routasalo P et al. (2005) Malnutrition and associated factors among aged residents in all nursing homes in Helsinki. Eur J Clin Nutr 59, 578-583.

8. Ahmed T \& Haboubi N (2010) Assessment and management of nutrition in older people and its importance to health. Clin Interv Aging 5, 207-216.

9. Brownie S (2006) Why are elderly individuals at risk of nutritional deficiency? Int J Nurs Pract 12, 110-118.

10. Siddhisena KAP (2005) Socio-Economic Implications of Ageing in Sri Lanka: An Overview. Working Paper no. WP105. Oxford: University of Oxford, Oxford Institute of Ageing.

11. Kshetrimayum N, Reddy CVK, Siddhana S et al. (2013) Oral health-related quality of life and nutritional status of institutionalized elderly population aged 60 years and above in Mysore City, India. Gerodontology 30, 119-125.

12. Israel GD (1992) Determining Sample Size. Document no. PEOD-6. Gainesville, FL: University of Florida, IFAS Extension.

13. World Health Organization (1989) Measuring Obesity: Classification and Description of Anthropometric Data. Report on a WHO Consultation of the Epidemiology of Obesity, Warsaw, 21-23 October 1987. Copenhagen: WHO Regional Office for Europe.

14. WHO Expert Consultation (2004) Appropriate body-mass index for Asian populations and its implications for policy and intervention strategies. Lancet 363, 157-163.
15. World Health Organization (1995) Physical Status: The Use and Interpretation of Anthropometry. Report of a WHO Expert Committee. WHO Technical Report Series no. 854. Geneva: WHO.

16. Rolland Y, Lauwers-Cances V, Cournot M et al. (2003) Sarcopenia, calf circumference, and physical function of elderly women: a cross-sectional study. J Am Geriatr Soc $\mathbf{5 1}$, 1120-1124.

17. Vellas B, Guigoz Y, Garry PJ et al. (1999) The Mini Nutritional Assessment (MNA) and its use in grading the nutritional state of elderly patients. Nutrition 15, $116-122$.

18. Gibson RS (2005) Principles of Nutritional Assessment, 2nd ed. New York: Oxford University Press.

19. Ministry of Health (2011) Food Based Dietary Guidelines for Sri Lankans, 2nd ed. Colombo: Nutrition Division, Ministry of Health.

20. Jayawardena R, Byrne NM, Soares MJ et al. (2013) Food consumption of Sri Lankan adults: an appraisal of serving characteristics. Public Health Nutr 16, 653-658.

21. Ruel MT (2003) Operationalizing dietary diversity: a review of measurement issues and research priorities. J Nutr 133, 11 Suppl. 2, 3911S-3926S.

22. Pirlich M \& Lochs H (2001) Nutrition in the elderly. Best Prac Res Clin Gastroenterol 15, 869-884.

23. Gariballa S \& Sinclair A (1998) Nutrition, ageing and ill health. BrJ Nutr 80, 7-23.

24. Bernstein MA, Tucker KL, Ryan ND et al. (2002) Higher dietary variety is associated with better nutritional status in frail elderly people. J Am Diet Assoc 102, 1096-1104.

25. Oldewage-Theron WH \& Kruger R (2008) Food variety and dietary diversity as indicators of the dietary adequacy and health status of an elderly population in Sharpeville, South Africa. J Nutr Elder 27, 101-133.

26. Rathnayake KM, Madushani PAE \& KDRR Silva (2012) Use of dietary diversity score as a proxy indicator of nutrient adequacy of rural elderly people in Sri Lanka. BMC Res Notes 5, 469.

27. Arimond M, Wiesmann D, Becquey E et al. (2010) Simple food group diversity indicators predict micronutrient adequacy of women's diets in 5 diverse, resource-poor settings. J Nutr 140, issue 11, 2059S-2069S.

28. Mirmiran P, Azadbakht L \& Azizi F (2006) Dietary diversity within food groups: an indicator of specific nutrient adequacy in Tehranian women. $J$ Am Coll Nutr 25, 354-361.

29. Torheim LE, Barikmo I, Parr C et al. (2003) Validation of food variety as an indicator of diet quality assessed with a food frequency questionnaire for Western Mali. Eur J Clin Nutr 57, 1283-1291.

30. Torheim LE, Ouattara F, Diarra MM et al. (2004) Nutrient adequacy and dietary diversity in rural Mali: association and determinants. Eur J Clin Nutr 58, 594-604.

31. Chen CCH, Schilling LS \& Lyder CH (2001) A concept analysis of malnutrition in the elderly. J Adv Nurs 36, 131-142.

32. Perera R \& Ekanayake L (2012) Relationship between nutritional status and tooth loss in an older population from Sri Lanka. Gerodontology 29, e566-e570.

33. Sharkey JR, Branch LG, Zohoori N et al. (2002) Inadequate nutrient intakes among homebound elderly and their correlation with individual characteristics and health-related factors. Am J Clin Nutr 76, 1435-1445.

34. Boyce J \& Shone G (2006) Effects of ageing on smell and taste. Postgrad Med J 82, 239-241.

35. Schiffman S \& Graham B (2000) Taste and smell perception affect appetite and immunity in the elderly. Eur J Clin Nutr 54, Suppl. 3, S54-S63.

36. Blechman MB \& Gelb AM (1999) Aging and gastrointestinal physiology. Clin Geriatr Med 15, 429-438. 
37. Parker BA \& Chapman IM (2004) Food intake and ageing the role of the gut. Mech Ageing Dev 125, 859-866.

38. Chapman IM, MacIntosh CG, Morley JE et al. (2002) The anorexia of ageing. Biogerontology 3, 67-71.

39. Timpini A, Facchi E, Cossi S et al. (2011) Self-reported socioeconomic status, social, physical and leisure activities and risk for malnutrition in late life: a cross-sectional populationbased study. J Nutr Health Aging 15, 233-238.
40. Shumaker NL, Ball AL, Neils-Strunjas J et al. (2003) Using memory strategies to improve 24-hour dietary recalls among older adults. J Allied Health 32, 196-201.

41. Amarasiri W (2006) Coconut fats. Ceylon Med J 51, 47-51.

42. Tsai AC \& Ku P-Y (2008) Population-specific Mini Nutritional Assessment effectively predicts the nutritional state and follow-up mortality of institutionalized elderly Taiwanese regardless of cognitive status. Br J Nutr 100, 152-158. 